\title{
millennium perspectives
}

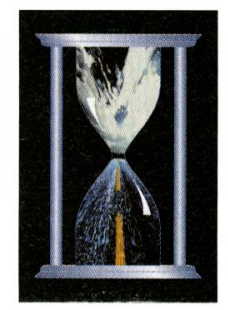

"Millennium Perspectives" is a special year-long section celebrating the new millennium. AMS Fellows, as recognized leaders in the fields served by the AMS, were asked to reflect on the close of this millennium and contribute brief essays on what they believe were significant issues or developments in the atmospheric and related oceanic and hydrologic sciences. They were also asked to predict what they believe will be the great challenges or developments yet to come.

A selection of essays will be published throughout the 2000 volume year. We thank those Fellows who have and continue to share their thoughts. We hope you find "Millennium Perspectives" interesting as well as thought provoking.

I have always regarded the heart of meteorology as being its practice in the public service, with weather forecasting as its centerpiece. Thus meteorology gets the public notice and the public funding it needs; otherwise it would not have become as large a field as it is.

With this point of view, there is no question in my mind that the most significant developments in the second millennium occurred in the nineteenth and twentieth centuries, and they were technological-the telegraph and the electronic computer. The birth of modern weather forecasting was enabled in the mid1800 s by the rapid collection of data by telegraphy, and the advent of the electronic computer in the mid1900 s resulted in the forecasting revolution that we have seen in the second half of the twentieth century. The development of forecast systems that followed the introduction of the new computers was inevitable, given the already existent classical mathematical and physical sciences and the meteorologists capable of using them. This is not to take away from the scien- tists who have done a yeoman's job of research and development; it's just inevitable that they would take advantage of the new, exciting tools that gave them such power and, yes, in the end, insight.

In looking forward to the third millennium, the lesson of the last is that unforeseeable developments in science and technology make the status of weather prediction unpredictable beyond a very few decades at most. However, computer power has grown exponentially, roughly doubling every two years, and has paced improvements in the guidance from numerical weather prediction. The increases in computer power are continuing and should affect numerical guidance early in the next century, as they have in the past. Also, I believe that the weather satellite will, in the future, have a far greater impact on weather forecasting than it has already achieved, but that will take new insights and developments.

Frederick G. Shuman

Fort WASHINGTON, MARYLAND
The best designed and most successful meteorological and oceanographic field experiment of the twentieth century was arguably the German Meteor expedition, 1925-27. With a single, specially de-

(C2000 American Meteorological Society signed ship, the Meteor, and a select team of researchers, it lasted three years and covered the Atlantic basin from the north all the way to the subantarctic waters. The results were published in a series of 14 volumes, of which the last appeared, delayed, after World War II, and in numerous monographs and articles. The expedition created a frame of reference for 
later field projects, and produced findings that have remained important to the present day. Just some of these are recalled here. Most impressive and still unparalleled is the mapping of the trade inversion, including inversion base, thickness, intensity, and humidity jump across the inversion. Wind profiles through the boundary layer were extensively measured. A rich documentation was collected on atmospheric tides. Attention was paid to evaporation processes and the relation of surface salinity to climate. Hydrographic soundings led to the development of the "core method" (Kernschichtmethode) of determining water masses. The first hydrographic section was laid across the South Atlantic, from Argentina to southwest Africa. Apart from creating a historical reference, this documented directly that the hydrospheric heat transport in the South Atlantic is directed toward rather than away from the equator. In the embryonal understanding of the global atmospheric-oceanic heat budget at that time, this seemed implausible, and no discomforting report appeared in the literature. Half a century later, from an indirect method and with a better appreciation of the role of continental placement for the oceanic heat transport, the measurements of the Meteor expedition were vindicated.

\section{Stefan Hastenrath \\ MADISON, WisCONSIN}

Predicting what will happen in the atmospheric and related sciences in the 2000 s is probably no more certain than predicting in 1900 what was to occur in the next 100 years. Extrapolation would not have been useful then and may not be now; yet that is what we are prone to do. I view the tremendous progress made in our technological evolution to be primarily due to 1) the development and fielding of major new observing systems (rawinsondes, radar, satellites, and automated surface observing systems over both land and water), 2) understanding the atmosphere, 3) digital computers of all sizes and the related communication systems, and 4) the national and international infrastructures necessary to reap the benefits of the technology and science. All have been important and represent our niche in the revolutions of the 1900s. Understanding the atmosphere would not have been possible without the routine measurements from the observing systems. Who is to say whether Richardson's experiment or Charney's recognition of why it failed was more important? Of course, a football field of people each computing at his or her own grid point would not have worked, but we now have a computer node successfully doing just about that. But to name one indispensable component - the computer chip.

During the next 100 years, the where, when, and how forecasts of geophysical phenomena are made will change dramatically. Continued development and implementation of remote sensing, computer, and communication systems will bring even greater understanding and increase our ability to model the oceans, atmosphere, and water cycle. Where forecasts of vari- ous types and projections into the future are made will evolve so that each component in our complex production and delivery systems will contribute to its maximum. Our increased efficiency will lead to even better low-cost service to the public. The very successful synoptic-scale atmospheric numerical models developed in the last 50 years will become coupled atmospheric-geopheric in nature and evolve along with their data assimilation systems both upscale (climate) and downscale (cloud scale), and prove indispensable to improvement in forecast performance measures at all time and space scales. But that, of course, is extrapolation.

Beyond extrapolation, out beyond the tip of the 200-mile pencil, or in this case the 25-year pencil, I foresee stochastic dynamic prediction of the Epstein/ Fleming variety rivaling Monte Carlo techniques for producing distributions (ensembles) of meteorological variables; this method will allow not only the uncertainty of the initial conditions but also the uncertainty of the model formulation itself to be taken into consideration. I also foresee the routine, operational use of sophisticated decision models where "weather" is a factor; this is an area whose surface has hardly been scratched. How to develop and implement models and how to educate users (decision makers) and meteorologists alike to make optimum use of our probabilistic forecasts, at all timescales, is an unsolved problem ripe for the government-private partnership.

Bob Glahn

Silver Spring, Maryland 


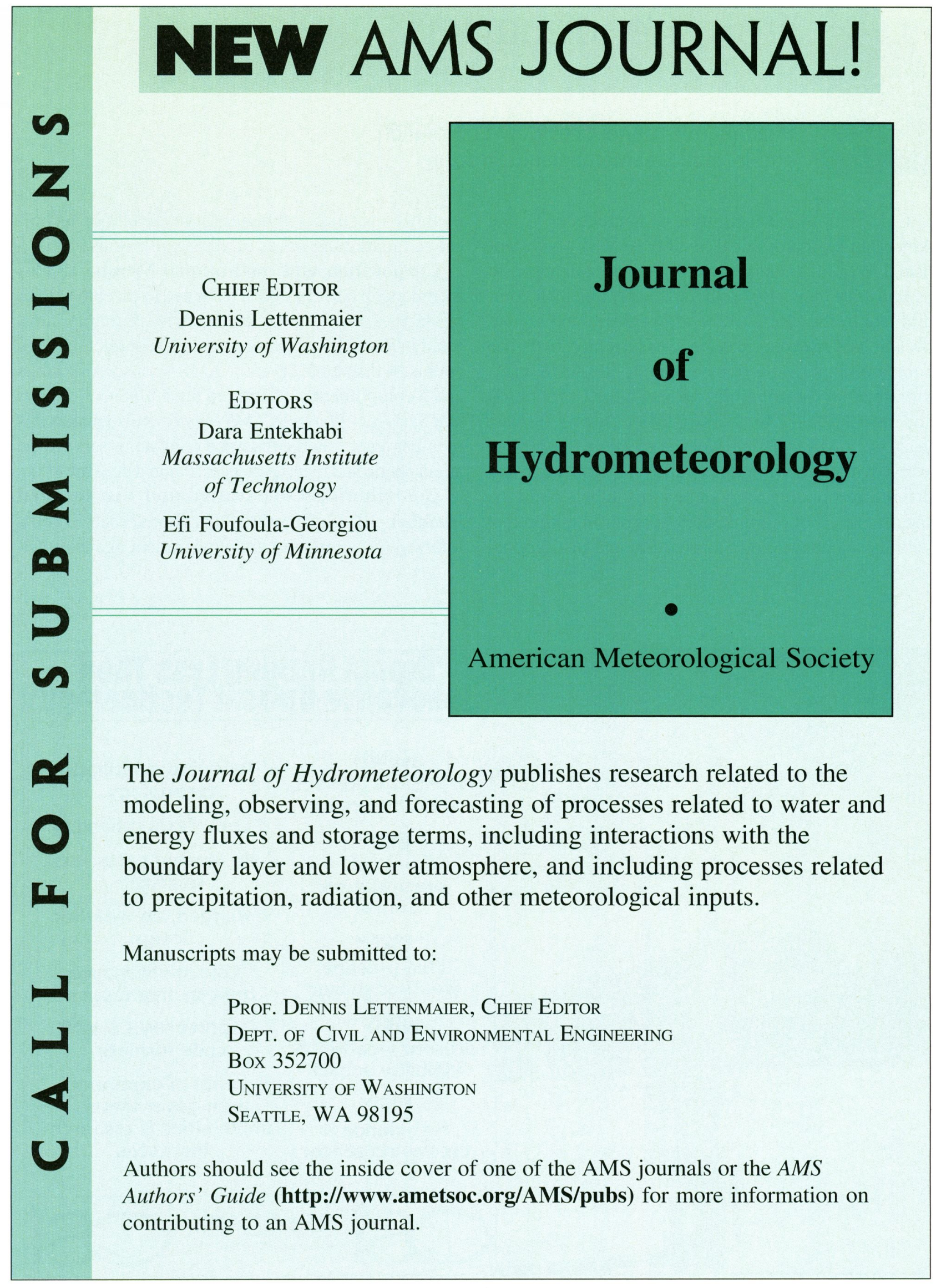

